\title{
3 次元多層ビット記録型光メモリ
}

\author{
田中拓男 $1,2,3$, 河田 聡 $1,2,3,4$ \\ 1 (独) 理化学研究所ナノフォトニクス研究室 (†351-0198 埼玉県和光市広沢 2-1) \\ 2阪大フロンティア研究機構 (テ565-0871 大阪府吹田市山田丘2-1) \\ 3 (独) 科学技術振興機構 戦略的創造研究推進事業 \\ ${ }^{4}$ 大阪大学 大学院工学研究科 ( $5565-0871$ 大阪府吹田市山田丘2-1)
}

\section{Three-Dimensional Multi-Layered Bit-Oriented Optical Storage}

\author{
Takuo TANAKA ${ }^{1,2,3}$ and Satoshi KAWATA ${ }^{1,2,3,4}$ \\ ${ }^{1}$ RIKEN (The Institute of Physical and Chemical Research), Nanophotonics Laboratory \\ 2-1 Hirosawa, Wako, Saitama 351-0198 \\ ${ }^{2}$ Handai Frontier Research Center 2-1, Yamada-oka, Suita, Osaka 565-0871 \\ ${ }^{3}$ Core Research for Evolutional Science and Technology \\ ${ }^{4}$ Graduate School of Engineering, Osaka University, 2-1, Yamada-oka, Suita, Osaka 565-0871
}

(Receied July 8, 2003)

\begin{abstract}
Three-dimensional multi-layered optical storage is one of the most promising methods that break the limitation of recording density in optical storage. It stores the bit information onto the multilayered recording planes inside the thick recording medium and realizes the tremendous large recording capacity. This paper describes the recording/reading principles, the systems, and the materials suitable for three-dimensional multi-layered memory. We also present the experimental results that using photochromic organic materials and rhodamine$\mathrm{B}$-doped and $\mathrm{Au}(\mathrm{III})$-doped PMMA for recording medium.
\end{abstract}

Key words: Three-dimensional microscopy, Optical memory, Confocal microscopy, Two-photon microscopy, Photochromic material

1.はじめに 〜2次元から3次元へ〜

VHSのビデオテープが急速にDVDへ置き換わろうとし ている。 ビデオテープとDVDの違いは何なのか? アアナロ グ記録とデジタル記録, 磁気記録と光記録などなど細か く上げてゆくとキリがないが，どちらも記録できるのは 約2時間の映像(映画)である。実際に記録されているもの だけを考えれば，DVDもVHSテープも大した違いはな い. 両者の本質的な違いは, 前者がリールに巻かれた テープに情報を記録する1次元記録なのに対し，後者が2 次元平面に広がったデイスクに情報を記録していること である。つまりDVDでは情報が平面に記録されているの で，好きな場所へ瞬時にジャンプできる。テープをリー ルに巻かなければならないビデオテープでは到底真似が できない．情報を記録する次元を1次元から 2 次元に高め たことで獲得したこの高いアクセススピードこそが， DVDの最も大きなメリットである。これは, 次世代の光 メモリの形態に対する1つの答えを与えてくれる. 本特集 でとりあげるようなテラバイトクラスの記憶装置を作る 場合は，単に容量が大きければ良いというものではな
い。必要な情報をすばやく記録・再生できることも重要 である、そのためには，これまで2次元に記録していた光 メモリの次元をさらに1つ増やして，3次元にするのが もっともシンプルでスマートな方法である (Fig. 1). 要す るに記録層を3次元的に多層にしてやれば良いわけで，こ れは普段読んでいる書籍が複数のページからできている のと同じである，誰も一枚の紙に小さな文字をビッシリ と印刷したり，大きな紙を持ち歩いたりはしない。人間 は昔から扱いやすいサイズのものを積み重ねるという3次 元多層記録を行ってきたのである.本報では，このビッ トデー夕の記録層を3次元的に多層化した多層記録光メモ リを取り上げ，その技術背景を解説するとともに，筆者 らが行った実験結果を紹介する。

\section{3次元多層光メモリを実現するには}

3次元多層記録のアイデアそのものは新しいものではな い. 既に様々な研究が行われ, 記録材料や記録原理, 記 録・再生光学系について多くの提案がなされている。例 えばRenzepisらのグループは，1989年にフォトクロミック 


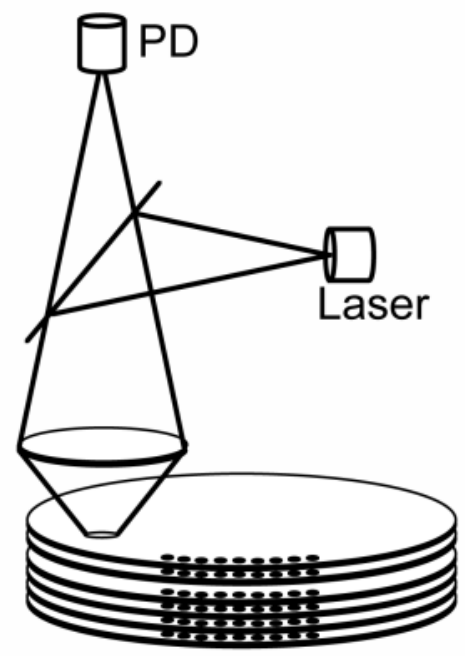

Fig. 1 Schematic diagram of three-dimensional multi-layered optical memory.

材料を用いた3次元光メモリを提案し1), 現在も精力的に 研究を行っている. Stricklerらは2光子吸収過程を用いて, 記録媒体中に局所的な屈折率変化を生じさせ，これを微 分干渉顕微鏡法により再生する手法を提案した2). 国内で も大阪大学において我々のグループが，1992年にまず フォトリフラクティブポリマーを用いて，ビット情報を 材料の屈折率変化として記録する3次元メモリを提案し $た^{3)}$.この材料は，書き換えのできないWrite-Once型のメ モリ材料であったが，その後 $\mathrm{LiNbO}_{3}$ などのフォトリフラ クティブ結晶や4-6)，フォトクロミック材料を用いた7,8) 書 き換え可能な 3 次元光メモリも提案した。静岡大学の Kawataは, ウレタンーウレア共重合体を記録材料に用 い，材料の光異性化反応を用いて情報を記録することに 成功している9). さらに我々は, ローダミンB色素と3価 の金イオンとの相互作用を利用して, 情報を蛍光分布と して記録する3 次元光メモリを中心に研究を進めてい る10).

一方，この3次元多層記録メモリとよく比較されるもの に多重記録型のボリュームホログラフィックメモリがあ るが，この両者に関して我々はその記録密度を解析的に 比較し, トータルの記録密度については, 多層記録ビッ 卜型光メモリの方が有利であることを示した ${ }^{11)}$ 。これ以 外にも国内外を通して多くの研究がなされている.

さて，この3次元多層記録を実現するには，情報を奥行 き方向に多層に記録, 再生できなければならない. とこ ろが, 現在の光メモリに使用されているピックアップ光 学系ではこれは実現できない. その理由は, 光学顕微鏡 の特性を考えれば解る。なぜならビット記録型光メモリ のピックアップは, ディスク上に記録された微小な凹凸 を光とレンズで観察しているわけで, ピックアップレン ズを顕微鏡の対物レンズ, 光ディスクを顕微鏡試料と考 えれば，これは光学顕微鏡と変わらないからである. Fig. 2(a) は, 一般に用いられるインコヒーレント照明の明視野 顕微鏡の3次元光学的伝達関数である ${ }^{12)}$. 網掛けを施した 領域は, 伝達関数が值を持つ領域であり, 横軸が光軸方 向の空間周波数 $\left(\mathrm{k}_{\mathrm{z}}\right)$ に対応し, 縦軸が面内(半径)方向の空
間周波数 $\left(\mathrm{k}_{\mathrm{r}}\right)$ に対応する。ここで重要なのは，この伝達関 数が $\mathrm{k}_{\mathrm{z}}$ 軸上に值を持っていないことである。これは, 試料 が持つ3次元構造のうち, 光軸方向(奥行き方向)の構造を この光学顕微鏡が全く像空間に伝達しないことを示して いる。つまり，たとえ物体が3次元的に広がった構造を 持っていても検出側 (観察側)ではこれを知ることができ ず，物体の像は単にボケるだけである。これは3次元物体 の構造の一断面を選択的に観察できないことでもある. このように書くと少々難しいが，顕微鏡を扱う場合試料 を薄くスライスして観察していたことを思い出せば良 い. 顕微鏡では，試料に厚みがあるとボケた像が邪魔を して観察できないので，あらかじめ物理的に破壊？して 奥行き方向の構造 (厚み)をなくしてから観察していたので ある。

光源にレーザーを用いるレーザー走査顕微鏡の3次元伝 達関数も, Fig. 2(a)のインコヒーレント照明顕微鏡の伝達 関数と全く同じであることが証明されている12)。つま り, 光ピックアップもやはり3次元的な空間周波数伝達帯 域を持たず，3次元空間に情報を記録したり再生すること ができないのである.

3次元物体を観察できないという光学顕微鏡の問題を解 決する手段として, 共焦点蛍光顕微鏡 13,14$)$ や 2 光子蛍光顕 微鏡がある ${ }^{15,16)}$. 共焦点蛍光顕微鏡と 2 光子蛍光顕微鏡の 3次元伝達関数をFig. 2(b), (c) に示す. また, 共焦点顕微 鏡の光学系をFig. 3に示す. 共焦点光学系がそれまでの顕 微鏡光学系と大きく異なるのは, 光の検出器が受光面積 の小さい点検出器で構成されており, 点光源であるレー ザーとレーザーの集光点, ならびに点検出器が互いに共 役な位置関係に配置されていることである。実際の装置 では図のように，小さな検出器を用いるのではなく光検 出器の前にピンホールを配置する. 原理の詳細は文献に 譲るが, ポイントは, レーザーの集光点以外からの光を このピンホールがカットするので, 焦点からはずれた光 はボケて重なるのではなく消えてしまい, 焦点を合わせ た位置の像だけが選択的に観察できることである，後述 するが，2光子顕微鏡では2光子過程の非線形性がこのピ ンホールと同様の効果を与える. いずれにしても, Fig. 2 (b)，（c）に示すようにこれらの光学系の伝達関数は $\mathrm{k}_{z}$ 軸

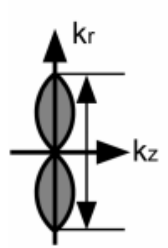

(a)

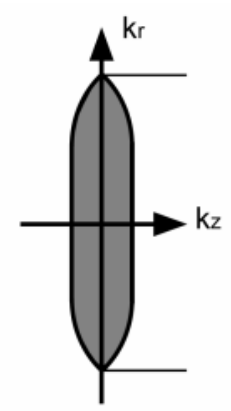

(b)

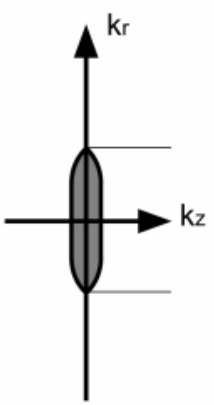

(c)
Fig. 2 Optical transfer functions. (a) incoherent illumination microscopy and laser scanning microscopy, (b)confocal fluorescent microscopy, and (c)two-photon fluorescent microscopy. 


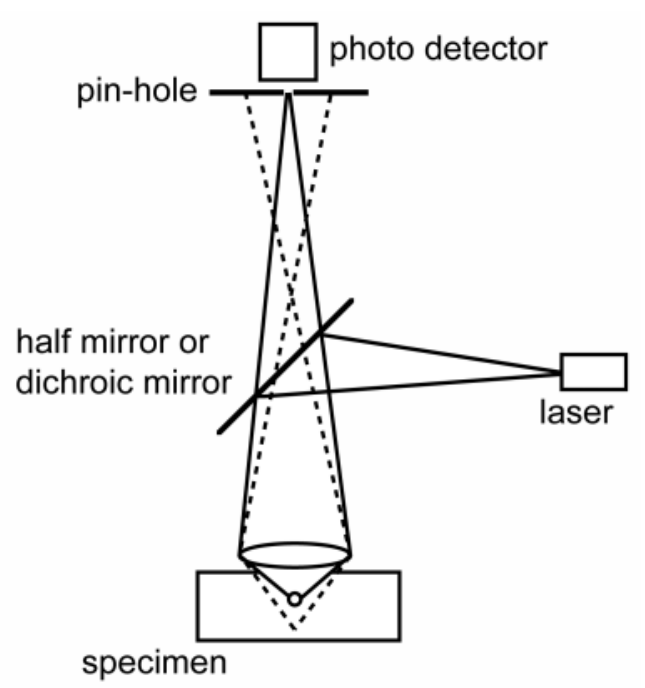

Fig. 3 Schematic optical setup of confocal microscope.

上に伝達帯域を持っており，物体の3次元情報を像空間に 伝達していることがわかる。（2光子顕微鏡の帯域が共焦 点蛍光顕微鏡と比べて小さいのは, 用いる光源の波長が2 倍長いためである). この光軸方向の伝達(結像) 能力は光 メモリのピックアップとしては，多層に記録されたデー 夕を1層ずつ選択的に分離して記録・再生できることを意 味しており，このような特性を持つ光学系を用いれば, Fig. 1に示したような, 多層記録のビット型光メモリが実 現できる.

\section{3次元多層ビット記録型光メモリの実際}

先にも述べたように3次元多層光メモリには，さまざま な手法が提案されている. 情報の記録方法だけでも, 記 録材料の屈折率変化として記録するものや, 吸収率, 反 射率, 蛍光発光強度の变化, さらには光学異方性の变化 で記録するものなどがある。ここでは，これらの中から フォトクロミック色素を用いたものと, 情報を蛍光発光

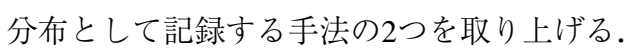

3. 1 フォトクロミック色素を用いた3次元光メモリ

フォトクロミック色素とは, 光照射によってその吸収 スペクトルが変化する色素である. 一例として九州大学 の入江らによって開発されたジアリルエテン系のフォト クロミック色素cis-1, 2-dicyano-1, 2-bis (2, 4, 5-trimethyl-3thienyl) ethane (B1536)を取り上げ, その化学構造をFig. 4 に，またその吸収スペクトルをFig. 5 に示す20)。この材料 は, 開環体と閉環体の $2 つ の$ 構造を持つ. 開環体では波長 $450 \mathrm{~nm}$ 以下にのみ強い吸収を持ち, 色は黄色である。こ の色素に紫色光を照射すると, 構造が開環体から閉環体 に変化する。すると, 波長 $512 \mathrm{~nm}$ 付近に新たな吸収帯が 現れ, そのスペクトルの変化に伴って色も黄色から赤色 へと変化する．閉環体の色素に500 nm付近の光を照射す ると, 逆の反応が起こり閉環体は開環体へ戻る。このよ うにフォトクロミック色素とは, 光照射により分子構造 が可逆的に変化し, その構造変化に伴い吸収スペクトル

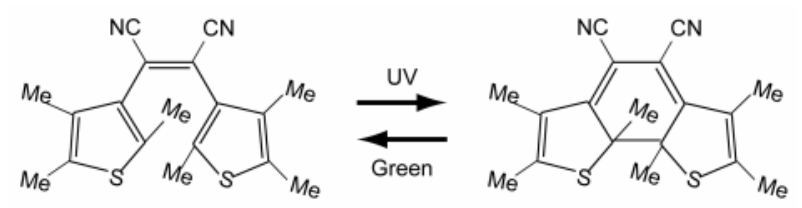

Fig. 4 Chemical structures of cis-1, 2-dicyano-1, 2-bis (2, 4,- trimethyl-3-thienyl) ethane (B1536) and photochemical reaction.

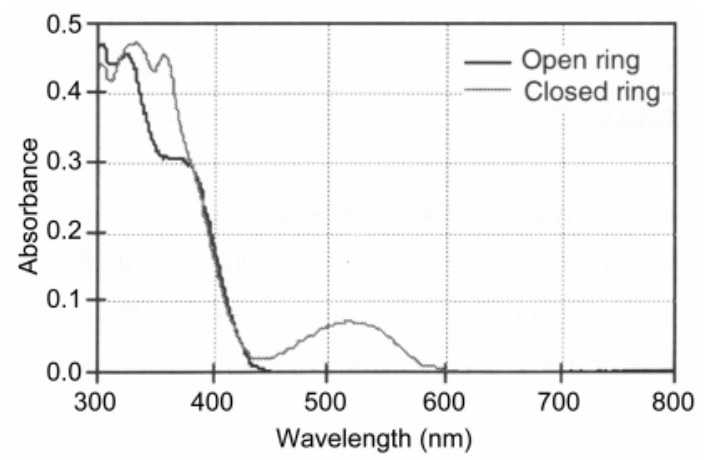

Fig. 5 Absorption spectra of B1536.

が変化する材料である。この可逆的な反応を利用する と，デー夕の書き換えができる光メモリを作ることがで きる。

フォトクロミック材料を3次元光メモリに利用する場合 は, フォトクロミズムを誘起する波長の光をそのまま照 射してはいけない。それは，レーザーを記録材料内部の 特定のデータ層だけに集光して照射しても，実際にはそ の上下の層にも光は照射されるので，これらの層のデー 夕も同時に書き換わってしまう(破壊されてしまう)からで ある。そこで利用するのが，2光子吸収という現象であ る。ふつう物質内の電子は, その物質のエネルギー ギャップと同じエネルギーを持つフォトンを1つ吸収し て, 基底状態から励起状態に遷移する。これを 1 光子吸収 過程という。一方, 2 光子吸収過程とは, 電子がエネル ギーギャップの半分に相当するエネルギーを持つフォト ンを2つ同時に吸収して励起状態に遷移する現象である. 光のエネルギーは, 光の振動数に比例し, また真空中の 波長に反比例するので, 例えば $400 \mathrm{~nm}$ に相当する吸収を 2 光子過程で起こすには, $800 \mathrm{~nm}$ の光を照射すればよい. この時重要なのは，1光子吸収が光強度に比例して起こる のに対し，2光子吸収は光強度の2乗に比例して起こるこ とである.この非線形性のために，2光子吸収はフォトン 密度の高い集光レーザースポット付近のみで起こり, 焦 点以外ではほとんど起こらない15)。つまり, この2乗特性 が共焦点光学系のピンホールと同じ作用を生み, これを 利用すれば, 3 次元空間内の局所的な 1 点のみで光反応を 起こしたり，その点からの信号だけを検出することがで きる.さらに光源は近赤外光を用いることになるので, 記録材料中での光の散乱効率が小さくなり，光を記録媒 体の奥深くまで到達させることができるというメリット も生まれる。

フォトクロミック光メモリの場合, データの再生方法 も慎重に検討しなければならない。デー夕を再生する時 
は，記録したデー夕を破壊せずに読み出さなければなら ないが，そのためには吸収率の変化つまり色素の色の変 化を情報として再生してはいけない，光を吸収させると フォトクロミック反応が誘起され, 分子が元に戻って情 報が消えてしまうからである。この問題を解決してデー 夕を非破壞で再生するには, 吸収スペクトルの変化に伴 う屈折率の变化を検出するのが良い. 例えば, Fig. 4に示 したB1536の場合, 波長 $650 \mathrm{~nm}$ 以上の波長域ではほとんど 吸収はないが，フォトクロミック反応によって生じた520 $\mathrm{nm}$ 付近の吸収帯による屈折率変化はこの波長域でも存在 する．この屈折率の変化を反射率の変化としてレーザー 走査共焦点反射顕微鏡で再生すれば, 高い3次元分解能で 非破壊に情報を再生することができる。

Fig. 6にジアリールエテンを用いた多層記録光メモリの 記録・再生実験の結果を示す。実験では, 記録光源に波 長780 nm, パルス幅80 fsecのチタンサファイアレーザー

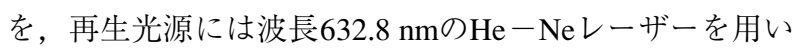
て, ビット間隔 $2 \mu \mathrm{m}$, 層間隔 $5 \mu \mathrm{m}$ で26層のデータを記録 再生した。最近では, ビット間隔 $1.5 \mu \mathrm{m}$, 層間隔 $3 \mu \mathrm{m}$ で 46層の記録再生に成功している。これは記録密度に換算 して13.2 GBit/in²に相当する.

同じくフォトクロミック色素を利用した3次元光メモリ として, Renzepisらのグループは, スピロピラン系の材料 を用いた手法を提案している1). 彼らも2光子吸収過程を

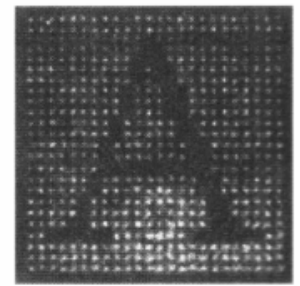

1st layer

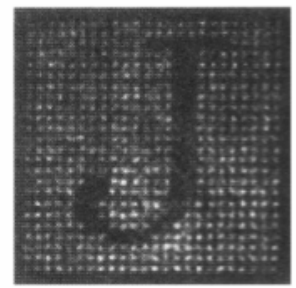

10th layer

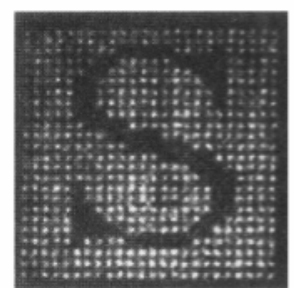

19th layer

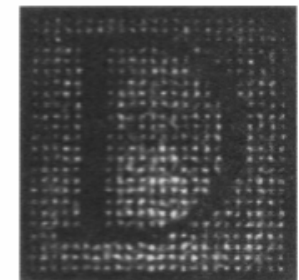

4th layer

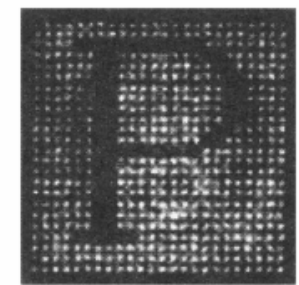

16th layer

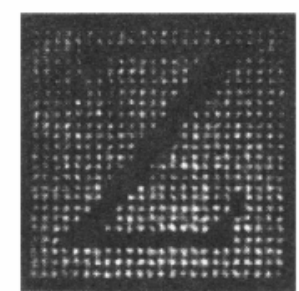

26th layer
$25 \mu \mathrm{m}$

Fig. 6 Readouts of bit patterns written into photochromic memory using B1536. The bit and layer intervals were 2 and $5 \mu \mathrm{m}$, respectively. The recorded data were read using a reflection confocal microscope.
利用しているが， 1 波長の光のみで2光子吸収を起こすの ではなく, Fig. 7のように, $1064 \mathrm{~nm}$ と $532 \mathrm{~nm}$ のつの波長 の光を使用し，両者が同時に照射された部位のみで光の 吸収が起こるという 2 波長の 2 光子吸収過程を利用してい る。そして2つのレーザー光をInformation beamと Addressing beamとみなして立方体の記録材料中に互いに直交する 方向から照射し，両ビームが重なるところのみで 2 光子反 応を励起させて3次元的に情報を記録している，また，再 生時にも2光子励起蛍光を用いて，記録したビットからの 蛍光発光として情報を再生している.

\section{2 蛍光記録型光メモリ}

試料からの蛍光発光分布を3次元的に観察できる共焦点 蛍光顕微鏡を光メモリに応用するには，情報を蛍光の発 光強度分布 (発光する/儿ななど) として記録できる材料 が必要である，例えば，Renzepisのグループは，ローダミ ン $\mathrm{B}$ 色素が $\mathrm{pH}$ 違いによって分子構造が変化し, その構造 変化に伴って蛍光発光が On/Offするという現象を利用した 記録材料を提案している18). また我々は同じローダミンB 色素を用いながらも, 金属錯イオンと蛍光色素の相互作 用を利用した記録材料を開発し，これを用いた3次元光メ モリを提案した10)

我々が開発した記録材料は, 塩化金酸とローダミン B色 素をポリメタクリル酸メチル樹脂 (PMMA)に分散させた ものである。この材料の蛍光分布の記録メカニズムを Fig. 8に示す. 塩化金酸から供給される3価の金イオン(以 下 $\mathrm{Au}(\mathrm{III}))$ がローダミンB分子の近くにあると，ローダミ ン $\mathrm{B}$ 分子の蛍光を光励起しても, 励起されたローダミン $\mathrm{B}$ 分子のエネルギーは $\mathrm{Au}(\mathrm{III})$ にエネルギー遷移し, 結果と してローダミンB分子はクエンチ (消光)される (Fig. (a)). この状態は, 記録材料に何も情報が記録されていない初 期状態に対応する。この材料に紫〜紫外領域の光 (波長 $310 \mathrm{~nm}$ に吸収ピーク)を照射すると, $\mathrm{Au}(\mathrm{III})$ は光化学反応

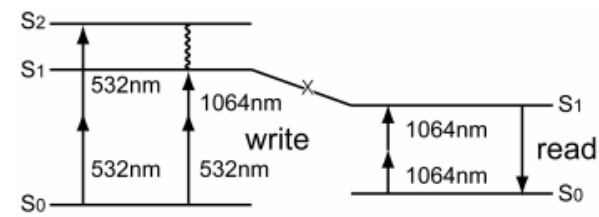

(a)

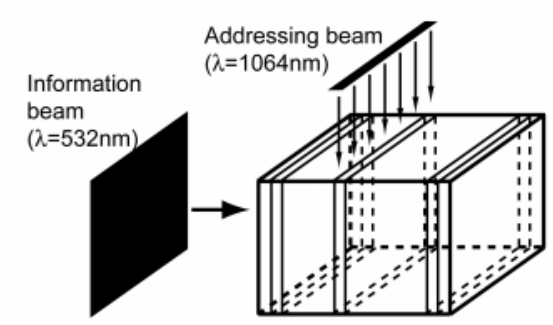

(b)

Fig. 7 Two-photon photochromic three-dimensional memory. (a) Schematic representation of "Write" and "Read" processes, (b) Two-photon 3D memory addressing with orthogonally propagating beams. 


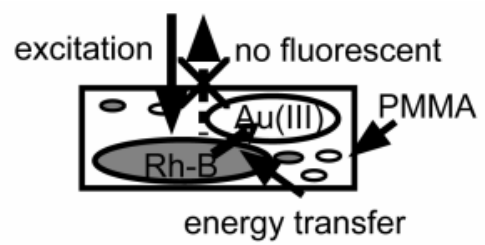

(a)

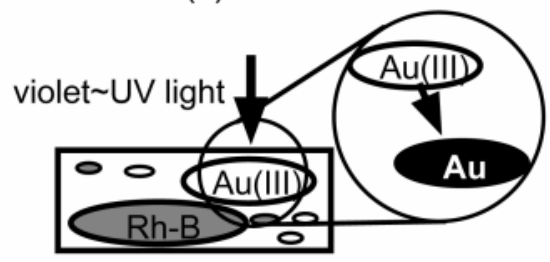

(b)

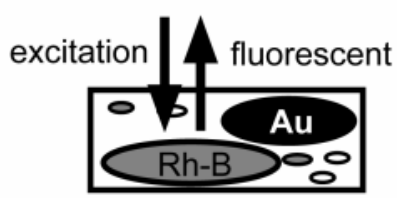

(c)

Fig. 8 The recording mechanism of the fluorescent patterns inside the $\mathrm{Au}$ (III)-doped and rhodamine-B doped PMMA medium. The details are given in the text.

もしくは熱反応により，ナノメートルサイズの金微粒子 に還元される (Fig. (b))．還元された金ナノ微粒子はAu (III) とはエネルギー状態が異なるので，エネルギー遷移が 起こらずローダミンBをクエンチしなくなる。つまり紫外 光を照射して金イオンを還元した領域のローダミン B分子 は，再活性され蛍光を発するようになる (Fig. (c) ) 19). 紫 外光の照射条件を調整して生成される金微粒子の粒径を 制御したり，ローダミンBの励起光の波長をうまく選択す ると，金微粒子表面に局在モードの表面プラズモンが励 起される ${ }^{20)}$ 。この時, 金微粒子表面の電場は数桁程度増 強されるので，これを利用すれば蛍光分子からさらに強 い蛍光を発光させることが可能となり, 再生信号のS/N比 が向上する。

実験で用いた記録材料は，メタクリル酸メチル (MMA) を溶媒として，これにPMMA，ローダミンBと塩化金酸を 混合した。これを充分に擋拌した後スライドガラス上に キャストして溶媒を揮発させポリマーフィルムを作成し た。実験に用いた記録光学系をFig. 9に示す。光源には, 波長 $441.6 \mathrm{~nm}$, 出力 $10 \mathrm{~mW}$ の He-Cdレーザーを使用した. このレーザー光をビームエキスパンダーでコリメート し，対物レンズで回折限界にまで集光した。用いた対物 レンズは 40 倍, $\mathrm{NA}=0.65$ である。記録材料は, $\mathrm{x}-\mathrm{y}-\mathrm{z}$ ス テージ上にセットし，コンピュータ制御により3次元走査 した。記録したデータのビット間隔は $5 \mu \mathrm{m}$ ，上下方向の デー夕層間隔は $10 \mu \mathrm{m}$ で，計5層の記録を行った。記録し たデー夕は，カールッァイス社製レーザー走査共焦点顕 微鏡LSM-410により再生した。再生光には, $\mathrm{He}-\mathrm{Ne}$ レー ザー $(543.5 \mathrm{~nm})$ を用いた。 Fig. 10がその実験結果である. それぞれの層の情報は高いコントラストで再生できてお り，上下の層からのクロストークもない。この結果から 共焦点蛍光顕微光学系のもつ高い3次元分解能の効果と 3

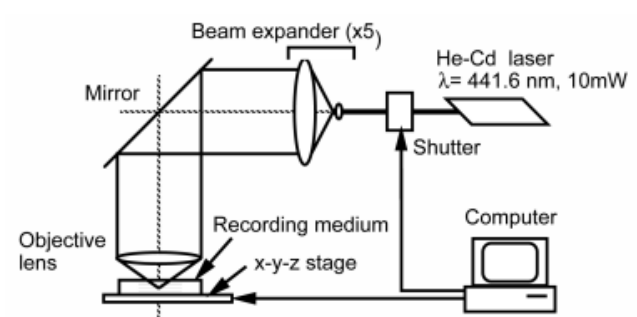

Fig. 9 Optical recording system for three-dimensional multi-layered memory.

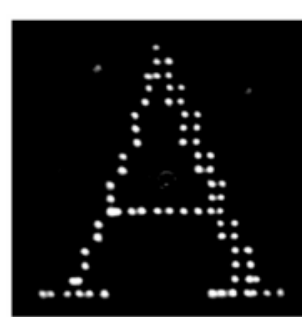

(a)

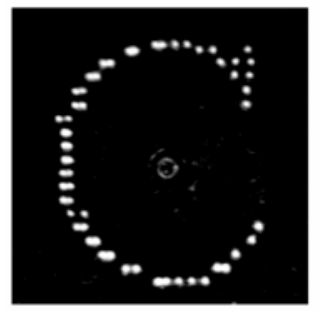

(c)

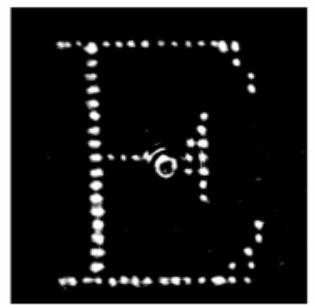

(e)

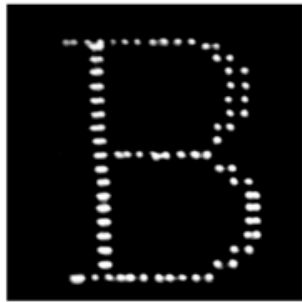

(b)

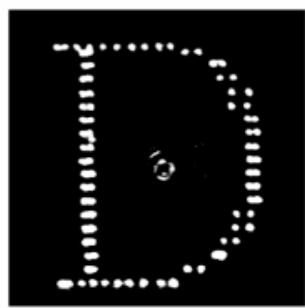

(d)

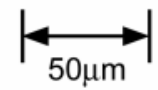

Fig. 10 Experimental results of three-dimensional recording. (a), (b), (c), (d) , and (e) are the first (neares to the medium's surface), second, third, fourth, and fifth layer, respectively. The bit data are recorded every $5 \times 5 \mu \mathrm{m}$ in a lateral plane, and the longitudinal distance between data planes is $10 \mu \mathrm{m}$.

次元光メモリへの有効性が確認できた.

\section{4. 今後の展望}

CDやDVDがこれだけ広く利用されている以上，次世代 の大容量光メモリもこれらを無視できない.3次元多層メ モリには，トラッキングの手法などこれまでのDVDの開 発で蓄積した多くの技術を利用でき，またこれまでの光 メモリと互換性を保つことが出来るという大きなメリッ 卜がある。もちろん新しく開発しなければならない技術 もある。例えば透明に近い記録材料の中に多層に記録し たデー夕層の中から，特定の1層だけに正確にフォーカス を合わせるには，奥行き方向も含めた 3 次元的なトラッキ 
ング方法を開発しなければならない。また2光子過程を用 いた光記録技術についても，小型・低消費電力の超短パ ルスレーザーの開発が必要である。しかし, 数年前では 単なる夢物語であったこれらの技術も，ここ数年の急速 な技術進歩により実現の可能性が見えてきた. 最先端の 技術を駆使すれば，近い将来必ずテラバイトクラスの超 大容量を持った光メモリが手に入るようになる．そうな れば我々はもう情報を取捨選択してから記録する必要は ない. 面倒なビデオの録画予約から解放され，各個人が 見たいもの聞きたいものなど好きな情報を好きなだけ記 録・保存できるようになる。テラバイトという容量は単 に $10^{12}$ バイトという数字だけの問題ではない. 携帯電話 が，それまでの電話のあり方やコミュニケーションの概 念を一変したように，超大容量の光メモリは情報記録の 概念に劇的な変化を与えるのである。

\section{参考文献}

1) D. A. Parthenopoulos and P. M. Rentzepis: Science, 245 (1989) 843
2) J. H. Strickler and W. W. Webb: Opt. Lett. 16 (1991) 1780.

3) S. Kawata, T. Tanaka, Y. Hashiomoto, and Y. Kawata: Proc. SPIE, 2042 (1993) 314.

4) Y. Kawata, H. Ueki, Y. Hashimoto, and S. Kawata: Appl. Opt. 34 (1995) 4105.

5) H. Ueki, Y. Kawata, and S. Kawata: Appl. Opt. 35 (1996) 2457.

6) Y. Kawata, T. Tanaka, and S. Kawata: Appl. Opt. 35 (1996) 5308.

7) A. Toriumi, J. Herrmann, and S. Kawata: Opt. Lett. 22 (1997) 555

8) A. Toriumi, S. Kawata, and M. Gu: Opt. Lett. 23 (1998) 1924.

9) M. Ishikawa, Y. Kawata, C. Egami, O. Sugihara, N. Okamoto, M. Tsuchimori, and O. Watanabe: Technical Digest of International Symposium on Optical Memory (ISOM) 1998 (1998) 142.

10) T. Tanaka and S. Yamamoto: Opt. Commun. 212 (2002) 45

11) T. Tanaka and S. Kawata: J. Opt. Soc. Am. A.13 (1996) 935

12) T. Wilson and C. J. R. Sheppard: THEORY AND PRACTICE OF SCANNING OPTICAL MICROSCOPY (Academic, London, 1985).

13) O. Nakamura and S. Kawata: J. Opt. Soc. Am. A, 7 (1990) 522.

14) C. J. R. Sheppard: Optik, 74 (1986) 128.

15) W. Denk, J. H. Strickler, and W. W. Webb: Science, 248 (1990) 73.

16) O. Nakamura and T. Okada: Optik, 100 (1995) 167.

17) M. Irie and M. Mohri: J. Org. Chem, 53 (1988) 803

18) A. S. Dvornikov and P. M. Rentzepis: Opt. Commun. 136 (1997) 1.

19) P. Xu and H. Yanagi: Chem. Mater. 11 (1999) 2626.

20) S. Kawata ed: Near-Field Optics and Surface Plasmon Polaritons (Springer, Berlin, 2001).

\section{レーザーワード}

共焦点顕微鏡 (confocal microscope)

共焦点顕微鏡とは，点光源からの光を対物レンズで集 光して試料を照明し, さらに試料からの光を再度対物レ ンズで集めて点光検出器で検出することにより, 厚みの ある試料中の特定の断面のみを観察できる顕微鏡であ る，通常，光源にはレーザーを用いるため，共焦点顕微 鏡はレーザー走査型顕微鏡であることが多い。また光検 出器は，検出器前面にピンホールを配置することによっ
て点検出器とする。一般的に, 光学顕微鏡では焦点が 合っている部位以外の光も重なって見えてしまうため像 がぼやけてしまうが，共焦点顕微鏡ではピンホールが焦 点面以外の光をカットするため厚い試料の特定の深さの 情報を選択的に観察することができる，さらに，厚みの ある試料のそれぞれの深度での像をパソコン上で合成す れば三次元構造を構築できる. 